\title{
Ternary Copolymerization of Carbon Dioxide with Optical Isomers of 1,2-Epoxypropane and Phenylepoxyethane
}

\author{
Shohei Inoue, Takashi Hirano, and Teiji Tsuruta \\ Department of Synthetic Chemistry, Faculty of Engineering, \\ University of Tokyo, Tokyo 113, Japan.
}

(Received October 28, 1976)

\begin{abstract}
In the copolymerization of the ternary system: carbon dioxide, $(\mathbf{R})-1,2-$ epoxypropane, and (R)- or (S)-phenylepoxyethane with diethylzinc-water catalyst, (R)as well as (S)-phenylepoxyethane are incorporated into the same copolymer chain with (R)-1,2-epoxypropane. From this fact, the selection of optical antipodes of epoxide by the enantiomorphic catalyst site mechanism is considered unlikely in this ternary system.

KEY WORDS Carbon Dioxide / Copolymerization / Epoxide / 1,2-

Epoxypropane / Optical Activity / Phenylepoxyethane / Polycarbon-

ate / Propylene Oxide / Stereoregularity / Styrene Oxide /
\end{abstract}

The alternating copolymerization of carbon dioxide and epoxide to form an aliphatic polycarbonate has been the subject of our detailed investigation..$^{1-3}$ One of the important unsolved problems is the tacticity or the sequential dis-

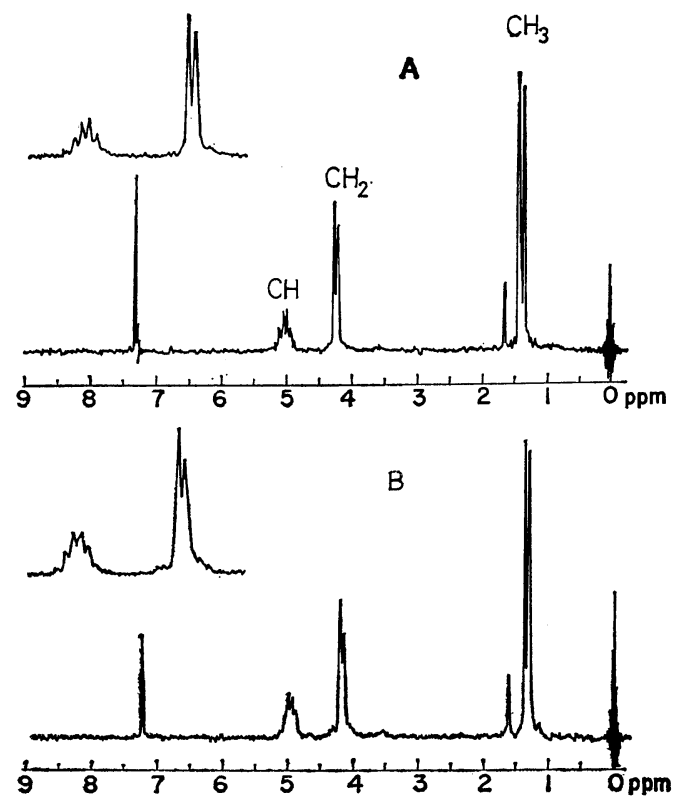

Figure 1. Proton NMR spectra of carbon dioxide(R)-1,2-epoxypropane copolymer (A) and carbon dioxide-(RS)-1,2-epoxypropane copolymer (B), in chloroform- $d$, at room temp, $100 \mathrm{MHz}$. tribution of optical antipodes of epoxide units in the copolymer from carbon dioxide and monosubstituted epoxide. For example, the copolymer of carbon dioxide and racemic 1,2epoxypropane, obtained by using diethylzincwater system as catalyst, is amorphous, ${ }^{4}$ and infrared, proton NMR (Figure 1), and carbon-13

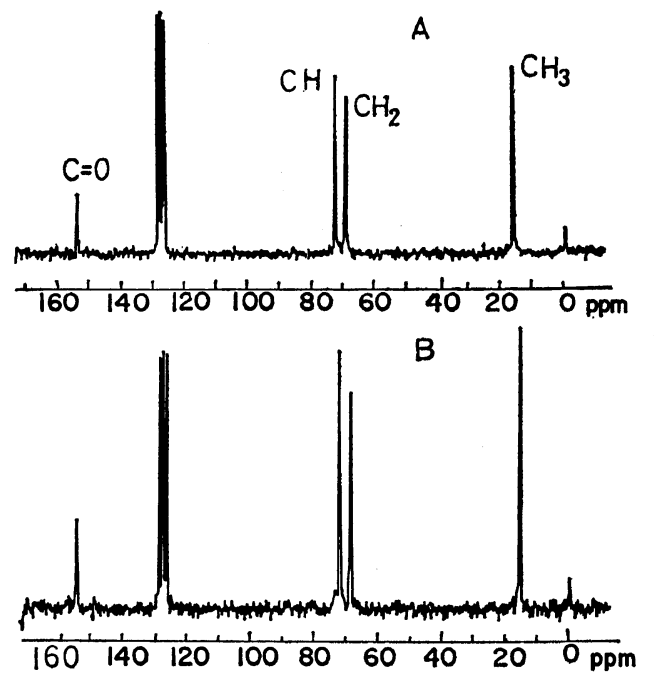

Figure 2. Carbon-13 NMR spectra of carbon dioxide-(R)-1,2-epoxypropane copolymer (A) and carbon dioxide-(RS)-1,2-epoxypropane copolymer (B), in benzene- $d_{6}$, at $50^{\circ} \mathrm{C}, 100 \mathrm{MHz}$, accumulated for 1600 and 800 times, respectively. 
NMR (Figure 2) spectra of the copolymer exhibit no differences from those of the carbon dioxide(R)-1,2-epoxypropane copolymer which should have predominantly an isotactic structure. ${ }^{5}$ Since the spectral information does not necessarily reflect the microstructure of the copolymers, the tacticity of the carbon dioxide-racemic 1,2epoxypropane copolymer remains unknown.

In order to obtain information about the reactivity of optical isomers of monosubstituted epoxide in the copolymerization with carbon dioxide, we have studied the ternary copolymerization of carbon dioxide with optical isomers of two different monosubstituted epoxides, 1,2epoxypropane and phenylepoxyethane, by examining whether the optical isomers of the two epoxides are incorporated into the same polymer chain to form a ternary copolymer or into different polymer chains to give a mixture of binary copolymers.

\section{RESULTS AND DISCUSSION}

Fractionation of Mixture of Carbon Dioxide(RS)-1,2-Epoxypropane Copolymer and Carbon Dioxide-(RS)-Phenylepoxyethane Copolymer

As the preliminary experiment for the ternary copolymerization, a fractionation of a mixture of carbon dioxide-(RS)-1,2-epoxypropane copolymer $\left([\eta]=0.7\right.$, benzene, $\left.35^{\circ} \mathrm{C}\right)$ and carbon di-

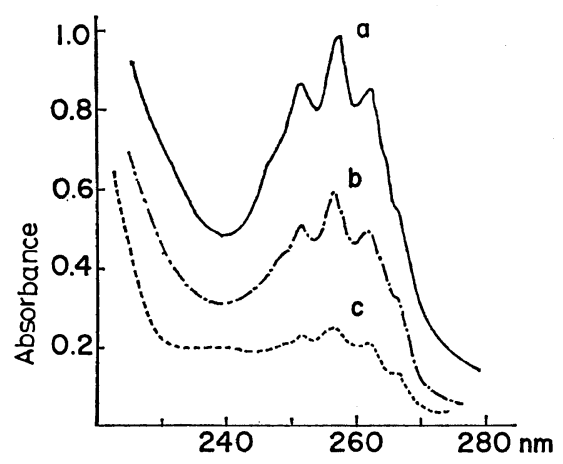

Figure 3. Ultraviolet spectra of fractions in the fractionation of a mixture of carbon dioxide(RS)-phenylepoxyethane copolymer $(0.15 \mathrm{~g})$ and carbon dioxide-(RS)-1,2-epoxypropane copolymer $(0.15 \mathrm{~g})$ in dioxane $(20 \mathrm{ml})$ by the addition of methanol (a) $19 \mathrm{~m} l$ (weight of the fraction, 23\% of the copolymers), (b) $24 \mathrm{~m} l$ (34\%), and (c) residual $(26 \%)$.
oxide-(RS)-phenylepoxyethane copolymer $([\eta]=$ 0.5 , benzene, $35^{\circ} \mathrm{C}$ ) was attempted. The same weights $(0.15 \mathrm{~g}$, respectively) of these copolymers were dissolved in dioxane $(20 \mathrm{~m} l)$, and methanol was added dropwise to the stirred solution in order to fractionally precipitate the copolymers. As seen in Figure 3, the mixture could substantially be separated into fractions with high and very low contents of phenylepoxyethane units, as indicated by the difference in the strengths of the ultraviolet absorption due to the phenyl group.

Ternary Copolymerization of Carbon Dioxide, $(R S)$-1,2-Epoxypropane, and (RS)-Phenylepoxyethane

Ternary copolymerization of carbon dioxide (55 atm) with equimolar amounts of (RS)-1,2epoxypropane (6.7 $\mathrm{g}$ ) and (RS)-phenylepoxyethane $(13.9 \mathrm{~g})$ was carried out by using diethylzincwater $(1: 1)$ catalyst system $(2.4 \mathrm{~mol} \%$ to the epoxides) in dioxane $(40 \mathrm{ml})$ at $35^{\circ} \mathrm{C}$ for two days, to give $2.47 \mathrm{~g}$ of a methanol insoluble copolymer with $[\eta] 1.4$ (benzene, $35^{\circ} \mathrm{C}$ ). The contents of epoxypropane, phenylepoxyethane, and carbon dioxide units of the copolymer were estimated to be 30,23 , and $47 \%$, respectively.

The copolymer was subjected to an attempted fractional precipitation from dioxane solution by methanol, as described above. The results shown in Figure 4 indicate that the contents of the phenylepoxyethane units of the fractions obtained

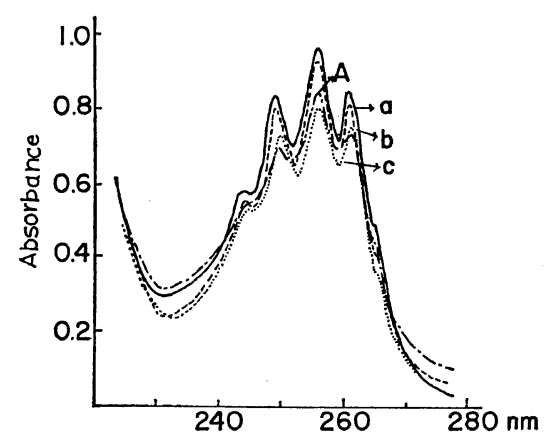

Figure 4. Ultraviolet spectra of fractions in the fractionation of carbon dioxide-(RS)-phenylepoxyethane-(RS)-1,2-epoxypropane copolymer $(0.40 \mathrm{~g})$ in dioxane $(25 \mathrm{~m} l)$ by the addition of methanol (a) $16 \mathrm{~m} l$ (weight of the fraction, $44 \%$ of the copolymer), (b) $26 \mathrm{ml}$ (36\%), and (c) residual (11\%); (A) unfractionated. 
are not much different from each other. Therefore, the copolymer obtained is not considered to be a mixture of two kinds of polycarbonate, carbon dioxide-1,2-epoxypropane copolymer and carbon dioxide-phenylepoxyethane copolymer, but a polycarbonate possessing monomeric units from the two species of epoxide along a main chain of the copolymer molecule.

Ternary Copolymerization of Carbon Dioxide, $(R)$ 1,2-Epoxypropane, and $(R)$ - or $(S)$-Phenylepoxyethane

In order to see how the optical antipodes of these epoxides are incorporated into the copolymer chain with carbon dioxide, the ternary copolymerization involving (R)-1,2-epoxypropane

Table I. Ternary copolymerization of carbon dioxide, (R)-1,2-epoxypropane(propylene oxide, $\mathrm{PO}$ ), and $(\mathbf{R})$ - or (S)-phenylepoxyethane(styrene oxide, SO) ${ }^{\mathrm{a}}$

\begin{tabular}{|c|c|c|c|c|c|}
\hline \multirow{3}{*}{ Monomerb } & \multicolumn{5}{|c|}{ Copolymer } \\
\hline & \multirow{2}{*}{$\begin{array}{l}\text { Yield, } \\
\mathrm{g}\end{array}$} & \multicolumn{3}{|c|}{ Composition, $\%$} & \multirow{2}{*}{$\stackrel{[\eta]}{\mathrm{d} l / \mathrm{g}}$} \\
\hline & & PO & SO & $\mathrm{CO}_{2}$ & \\
\hline$(\mathrm{R})-\mathrm{PO} \cdot(\mathrm{R})-\mathrm{SO} \cdot \mathrm{CO}_{2}$ & 2.22 & 36.1 & 19.8 & 44.1 & 0.30 \\
\hline (R)-PO $\cdot(\mathrm{S})-\mathrm{SO} \cdot \mathrm{CO}_{2}$ & 2.72 & 35.1 & 19.4 & 45.5 & 0.50 \\
\hline \multicolumn{6}{|c|}{$\begin{array}{l}\text { PO } 5.0 \mathrm{~g} \text {, SO } 10.5 \mathrm{~g} \text { (equimolar ratio); diethyl- } \\
\text { zinc-water }(1: 1) \text { catalyst } 5.7 \mathrm{~mol} \% \text { to monomer; } \\
\mathrm{CO}_{2}, 65 \mathrm{~atm}, \text { dioxane, } 50 \mathrm{ml} ; 35^{\circ} \mathrm{C} ; 2 \text { days. } \\
\text { (R)-PO, }[\alpha]_{\mathrm{D}}^{22}+12.67 \text { (neat); (R)-SO, }[\alpha]_{\mathrm{D}}^{22}+32.13 \\
\text { (neat); (S)-SO, }[\alpha]_{\mathrm{D}}^{22}-31.97 \text { (neat). }\end{array}$} \\
\hline
\end{tabular}

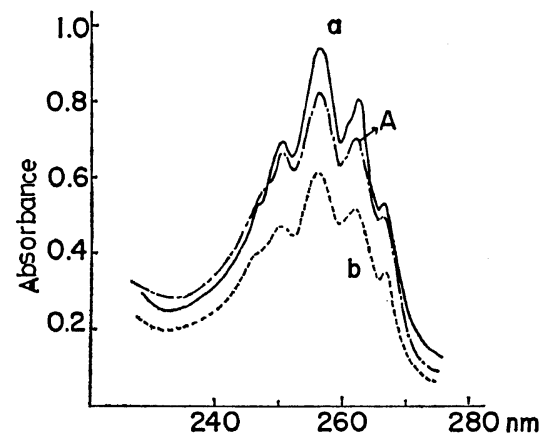

Figure 5. Ultraviolet spectra of fractions in the fractionation of carbon dioxide-(R)-phenylepoxyethane-(R)-1,2-epoxypropane copolymer $(0.30 \mathrm{~g})$ in dioxane $(20 \mathrm{~m} l)$ by the addition of methanol (a) $20 \mathrm{ml}$ (weight of the fraction, 24.3\% of the copolymer) and (b) residual (60.8\%); (A) unfractionated.

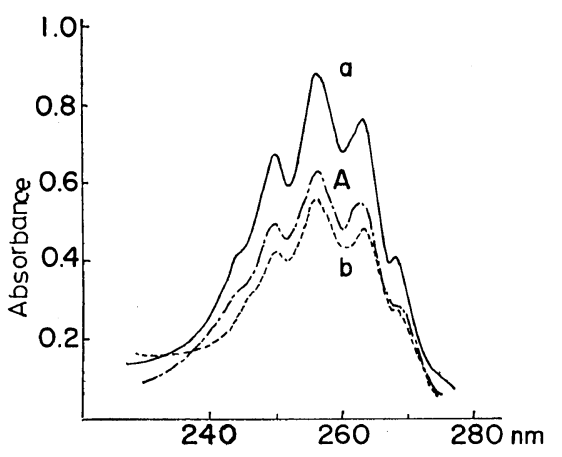

Figure 6. Ultraviolet spectra of fractions in the fractionation of carbon dioxide-(S)-phenylepoxyethane-(R)-1,2-epoxypropane copolymer $(0.30 \mathrm{~g})$ in dioxane $(20 \mathrm{ml})$ by the addition of methanol (a) 20 $\mathrm{m} l$ (weight of the fraction, 9.8\% of the copolymer) and (b) residual (76.2\%); (A) unfractionated.

and the optical antipodes of phenylepoxyethane was examined (Table I). The copolymers obtained from (R)-1,2-epoxypropane and ( $R$ )-phenylepoxyethane and from (R)-1,2-epoxypropane and (S)-phenylepoxyethane showed no differences in their infrared and NMR spectra. These copolymers were similarly subjected to an attempted fractionation to give the results shown in Figures 5 and 6 . In the cases of both copolymers, the contents of phenylepoxyethane units of the two fractions obtained are not considered very different. Thus, in both cases the products are not the mixture of binary copolymers, and (R)as well as (S)-phenylepoxyethane are considered to be incorporated into the same copolymer chain with (R)-1,2-epoxypropane and carbon dioxide.

Ternary Copolymerization of Carbon Dioxide, (RS)-1,2-Epoxypropane, and (S)-Phenylepoxyethane

In order to investigate further the reactivity of the optical antipodes of 1,2-epoxypropane when incorporated into the same copolymer molecule with (S)-phenylepoxyethane, (RS)-1,2-epoxypropane was copolymerized with (S)-phenylepoxyethane and carbon dioxide, and the copolymer was hydrolyzed to isolate epoxypropane unit in a form of the corresponding glycol which was derived to the bis(trimethylsilyl) ether. By the examination of the optical activity of this compound it is possible to know if the selection of 
the optical antipodes of 1,2-epoxypropane took place in the copolymerization.

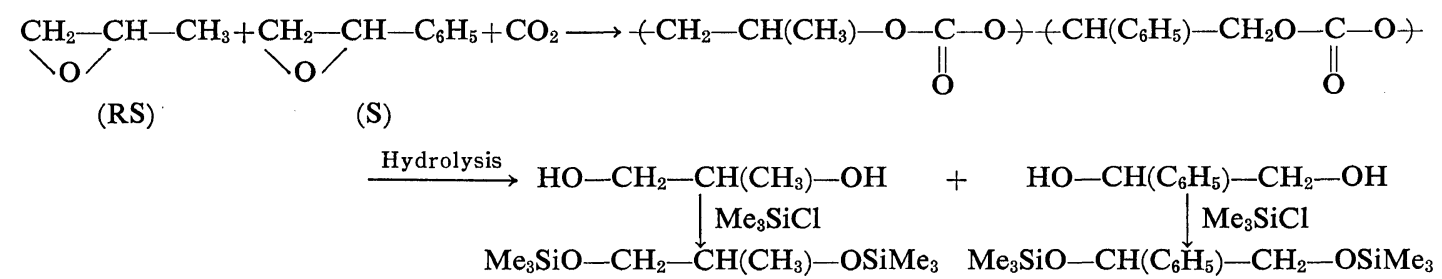

The copolymerization of carbon dioxide (55 atm) with equimolar amounts of (RS)-1,2-epoxypropane $(6.7 \mathrm{~g})$ and $(\mathrm{S})$-phenylepoxyethane $\left([\alpha]_{\mathrm{D}}^{22}\right.$ -37.1 (neat); $13.9 \mathrm{~g})$ by diethylzinc-water $(1: 1)$ catalyst system $(2.4 \mathrm{~mol} \%$ to the epoxides) in dioxane $(20 \mathrm{ml})$ at $35^{\circ} \mathrm{C}$ for four days gave $3.23 \mathrm{~g}$ of a methanol insoluble copolymer with [ $\eta] 1.3$ (benzene, $35^{\circ} \mathrm{C}$ ) and with the contents of epoxypropane, phenylepoxyethane, and carbon dioxide units of 39,14 , and $47 \%$, respectively.

As the results of the attempted fractionation (Figure 7) indicate, the product is not considered to be a mixture of binary copolymers. Of the fractions obtained, the parts relatively rich and relatively poor in the content of phenylepoxyethane were separately subjected to hydrolysis and the glycols corresponding to 1,2-epoxypropane and phenylepoxyethane units were isolated as the bis (trimethylsilyl) ethers. The results summarized in Table II show that the ( $R$ )-antipode of (RS)-1.2-epoxypropane reacted selectively, though slightly, in the copolymerization with

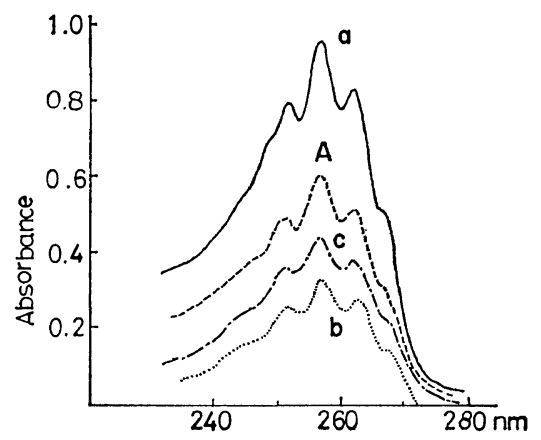

Figure 7. Ultraviolet spectra of fractions in the fractionation of carbon dioxide-(S)-phenylepoxyethane-(RS)-1,2-epoxypropane copolymer $(0.10 \mathrm{~g})$ in dioxane $(10 \mathrm{~m} l)$ by the addition of methanol (a) $19 \mathrm{ml}$ (weight of the fraction, $18 \%$ of the copolymer), (b) $24 \mathrm{ml}(42 \%)$, and (c) residual (26\%); (A) unfractionated.
(S)-phenylepoxyethane and carbon dioxide. The sense of the antipode of 1,2-epoxypropane which is rich in the copolymer was found the same in both fractions, but the selectivity appears higher in the fraction with higher content of (S)-phenylepoxyethane.

The optical activity of the bis (trimethylsilyl) ether from the phenylepoxyethane unit in this ternary copolymer (both fractions) coincides with that obtained from carbon dioxide-(S)-phenylepoxyethane binary copolymer. ${ }^{6}$ This fact indicates that the mode of ring opening of phenylepoxyethane does not change in binary and ternary copolymerizations.

\section{Discussion}

In the homopolymerization of (RS)-1,2-epoxypropane by organozinc catalyst system, a part of the product is an isotactic polymer which has been considered to be formed via the 'enantiomorphic catalyst site mechanism,' where the R and $\mathrm{S}$ sites on the catalyst are assumed to react

Table II. Optical rotation of trimethylsilyl ethers derived from 1,2-epoxypropane (PO) and phenylepoxyethane (SO) units in fractions from carbon dioxide-(RS)-1,2-epoxypropane-(S)-phenylepoxyethane copolymer

\begin{tabular}{lcccccc}
\hline & \multicolumn{3}{c}{ Composition, \% } & \multicolumn{2}{c}{$\begin{array}{c}\text { Optical rotation of } \\
\text { bis(trimethylsilyl) } \\
\text { ether, from }\end{array}$} \\
\cline { 2 - 3 } \cline { 7 - 7 } & PO & SO & $\mathrm{CO}_{2}$ & $\begin{array}{c}\text { PO unit, } \\
{[\alpha]_{300}^{24 \mathrm{~b}}}\end{array}$ & $\begin{array}{c}\text { SO unit, } \\
{[\alpha]_{\mathrm{D}}^{22 \mathrm{c}}}\end{array}$ \\
\hline a & 22 & 30 & 48 & & -1.26 & -50.5 \\
$\mathrm{~b}^{\mathrm{b}}$ plus c & 41 & 11 & 48 & & -0.61 & -50.2 \\
\hline
\end{tabular}

a See Figure 7.

b (R)-antipode of $\left(\mathrm{CH}_{3}\right)_{3} \mathrm{Si}-\mathrm{O}-\stackrel{*}{\mathrm{C}} \mathrm{H}\left(\mathrm{CH}_{3}\right)-\mathrm{CH}_{2}-$ $\mathrm{O}-\mathrm{Si}\left(\mathrm{CH}_{3}\right)_{3},[\alpha]_{300}^{24}-18.0$ (neat), obtained from (R)-1,2-propanediol with $[\alpha]_{D}^{25}-13.75$ (neat).

c (S)-antipode of $\left(\mathrm{CH}_{3}\right)_{3} \mathrm{Si}-\mathrm{O}-\stackrel{*}{\mathrm{C}} \mathrm{H}\left(\mathrm{C}_{6} \mathrm{H}_{5}\right)-\mathrm{CH}_{2}-$ $\mathrm{O}-\mathrm{Si}\left(\mathrm{CH}_{3}\right)_{3},[\alpha]_{\mathrm{D}}^{22}+54.9$ (neat). ${ }^{6}$ 
Table III. Assumed 'enantiomorphic catalyst site mechanism' in ternary copolymerization of carbon dioxide with optical isomers of 1,2-epoxypropane (PO) and phenylepoxyethane (SO)

\begin{tabular}{lcc}
\hline \multirow{2}{*}{ Monomer } & \multicolumn{2}{c}{ Polymer formed on } \\
\cline { 2 - 3 } & R-site of catalyst & S-site of catalyst \\
\hline (RS)-PO-(RS)-SO. $\mathrm{CO}_{2}$ & $-(\mathrm{R})-\mathrm{PO}-\mathrm{CO}_{2}-(\mathrm{R})-\mathrm{SO}-\mathrm{CO}_{2}-$ & $-(\mathrm{S})-\mathrm{PO}-\mathrm{CO}_{2}-(\mathrm{S})-\mathrm{SO}-\mathrm{CO}_{2}-$ \\
$(\mathrm{R})-\mathrm{PO} \cdot(\mathrm{R})-\mathrm{SO} \cdot \mathrm{CO}_{2}$ & $-(\mathrm{R})-\mathrm{PO}-\mathrm{CO}_{2}-(\mathrm{R})-\mathrm{SO}-\mathrm{CO}_{2}-$ & none \\
$(\mathrm{R})-\mathrm{PO} \cdot(\mathrm{S})-\mathrm{SO} \cdot \mathrm{CO}_{2}$ & $-(\mathrm{R})-\mathrm{PO}-\mathrm{CO}_{2}-$ & $-(\mathrm{S})-\mathrm{SO}-\mathrm{CO}_{2}-$ \\
$(\mathrm{RS})-\mathrm{PO} \cdot(\mathrm{S})-\mathrm{SO} \cdot \mathrm{CO}_{2}$ & $-(\mathrm{R})-\mathrm{PO}-\mathrm{CO}_{2}-$ & $-(\mathrm{S})-\mathrm{PO}-\mathrm{CO}_{2}-(\mathrm{S})-\mathrm{SO}-\mathrm{CO}_{2}-$ \\
\hline
\end{tabular}

selectively with the $\mathbf{R}$ and $\mathbf{S}$ antipodes of the epoxide. $^{7}$

If a similar mechanism of the selection of optical isomers of epoxide were operating in the copolymerization with carbon dioxide, the observations as described in Table III would be made in the ternary copolymerization of carbon dioxide and optical isomers of two different epoxides. For example, in the copolymerization involving the $\mathrm{R}$ antipode of one of the epoxides and the $S$ antipode of the other, a mixture of binary copolymers would be formed. On the other hand, in the combination of $\mathrm{R}$ antipodes of both epoxides a ternary copolymer would be the product. Furthermore, in the combination of a racemic epoxide and, for example, the $S$ antipode of another epoxide, a mixture of a binary copolymer and a ternary copolymer would be formed, where the sense of the antipode of the unit from the former epoxide would be reversed in the binary and ternary copolymers.

However, in copolymerizations of the ternary system: carbon dioxide, (R)-1,2-epoxypropane, and (R)- or (S)-phenylepoxyethane, the formation of a mixture of binary copolymers could not be observed. In the (RS)-1,2-epoxypropane-(S)phenylepoxyethane system, a slight selection of one of the antipodes of 1,2-epoxypropane was observed, but the sense of the antipode of the unit from this epoxide in the product was the same in fractions with different epoxide compositions. Therefore, it may be concluded that the selection of optical antipodes of epoxide by such a mechanism is not predominant, at least to any observable extent, in the copolymerization of the ternary system: carbon dioxide, 1,2-epoxypropane, and phenylepoxyethane. A slight selection of one of the antipodes of (RS)1,2-epoxypropane observed in the copolymerization with (S)-phenylepoxyethane and carbon dioxide would be due to the difference in reactivity of the (S)-phenylepoxyethane unit at the growing terminal toward the antipodes of 1,2epoxypropane as an entering monomer.

\section{EXPERIMENTAL}

\section{Monomer}

(R)-1,2-epoxypropane was prepared according to the following procedure: $:^{5,8,9}$

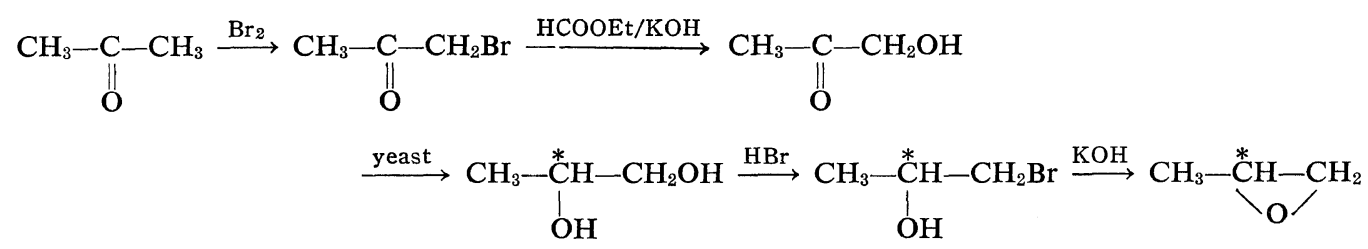

(R)- or (S)-phenylepoxyethane was obtained by the following procedure, as previously described: ${ }^{6}$

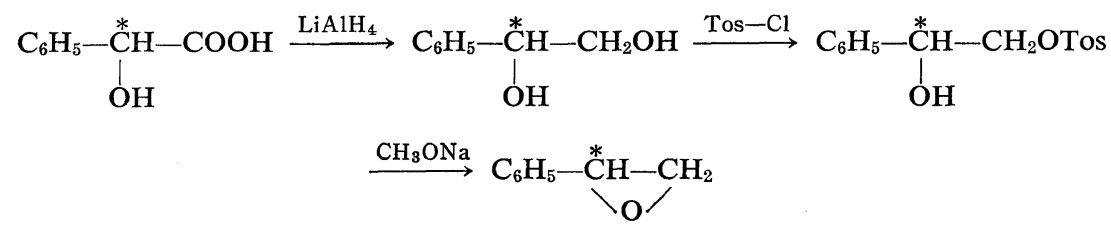




\section{Copolymerization}

Binary and ternary copolymerizations of carbon dioxide and epoxide were carried out as previously describe ${ }^{10}$ using diethylzinc-water (1 : 1$0.9)$ system as catalyst in dioxane at $35^{\circ} \mathrm{C}$ under a pressure $(55-65 \mathrm{~atm})$ of carbon dioxide. The reaction mixture was diluted with benzene, washed with dilute hydrochloric acid and then with aqueous sodium bicarbonate solution, and added to methanol to separate the copolymer as a precipitate.

\section{Fractionation of Copolymer}

To a dioxane solution of copolymer was added dropwise a definite amount of methanol, and the precipitates formed were collected by centrifugation, dissolved again in dioxane, then reprecipitated into a large amount of methanol. The residual solution was concentrated and added dropwise to a large amount of methanol to recover the remaining copolymer.

\section{Determination of Copolymer Composition}

The content of phenylepoxyethane units in the ternary copolymer may be roughly but conveniently measured by the ultraviolet spectrum of the copolymer in dioxane solution $(8.0 \mathrm{~g} / l)$. Quantitatively, the ratio of phenylepoxyethane and 1,2-epoxypropane units was obtained from the proton NMR spectrum of the copolymer in chloroform- $d\left(\mathrm{C}_{6} \mathrm{H}_{5}, \delta 7.2 \mathrm{ppm} ; \mathrm{CH}_{3}, \delta 1.3 \mathrm{ppm}\right)$. Combining this ratio with the results of elemental analysis, the contents of carbon dioxide, phenylepoxyethane, and 1,2-epoxypropane units were calculated.

Hydrolysis of Copolymer

Hydrolysis of the copolymer to obtain the epoxide unit as glycol and its isolation in the form of bis(trimethylsilyl) ether were carried out as described previously. ${ }^{6}$

\section{Measurements}

Ultraviolet spectra were measured by using a Shimadzu model MPS-50L spectrophotometer, infrared spectra by a Hitachi model EPI-G3 spectrophotometer, NMR spectra by a JEOL model PS-100 spectrometer, optical rotation by a Perkin-Elmer polarimeter model 241, and optical rotatory dispersion by a Nippon Bunko spectropolarimeter model ORD/UV-5.

\section{REFERENCES}

1. S. Inoue, "Progress in Polymer Science Japan," Vol. 8, Kodansha, Tokyo, 1975, p 1.

2. S. Inoue, T. Tsuruta, T. Takada, N. Miyazaki, M. Kambe, and T. Takaoka, Appl. Polym. Symp., 26, 257 (1975).

3. S. Inoue, Chemtech., 6(9), 588 (1976).

4. K. Udipi and J. K. Gillham, J. Appl. Polym. Sci., 18, 1575 (1974).

5. S. Inoue, H. Koinuma, and T. Tsuruta, Polym. J., 2, 220 (1971).

6. T. Hirano, S. Inoue, and T. Tsuruta, Makromol. Chem., 176, 1913 (1975).

7. T. Tsuruta, S. Inoue, N. Yoshida, and Y. Yokota, ibid., 81, 191 (1965).

8. P. A. Levene and A. Walti, J. Biol. Chem., 68, 415 (1926).

9. C. C. Price and M. Osgan, J. Am. Chem. Soc., 78, 4787 (1956).

10. S. Inoue, H. Koinuma, and T. Tsuruta, Makromol. Chem., 130, 210 (1969). 